\title{
Lenses of extremely cold water in the central Ionian Sea
}

\author{
Jürgen SELLSCHOPP *, Reiner ONKEN \\ Saclant Undersea Research Centre, Viale San Bartolomeo 400, 19138 La Spezia, Italy
}

Received 19 October 1999; revised 3 December 1999; accepted 14 December 1999

\begin{abstract}
Two lenses of cold water with core temperature $12.5^{\circ} \mathrm{C}$ were observed in the central Ionian Sea between the thermocline and the salinity maximum due to Levantine Intermediate Water. The estimated salinity in the lenses is 37.8. The relevance of the observation is assured by the high number of expendable probes deployed. The lens diameters are estimated at $30 \mathrm{~km}$. Analogy with a less spectacular feature contained in oceanographic measurements in the following year implies that the lenses rotate clockwise. The cold water lenses originate from the Adriatic Sea with a generation mechanism equivalent to meddy formation at the Iberian peninsula (eddy of Mediterranean water in the Atlantic Ocean). Year to year differences in cold lens generation are expected to be high. (C) 2000 Ifremer/CNRS/IRD/Éditions scientifiques et médicales Elsevier SAS
\end{abstract}

water mass / lens / meddy / Ionian /Adriatic

Résumé - Lentilles d'eau froide au centre de la mer Ionienne. Deux lentilles d'eau froide ont été observées au centre de la mer Ionienne entre la thermocline et la zone de salinité maximale de l'Eau Intermédiaire Levantine. Leur température est de $12,5^{\circ} \mathrm{C}$ et leur salinité est estimée à 37,8 . Cette observation est validée par le très grand nombre de sondes largables déployées sur cette zone. Le diamètre des lentilles est estimé à $30 \mathrm{~km}$. L'analogie avec un phénomène moins spectaculaire, observé l'année suivante, indique que ces lentilles tournent dans le sens anticyclonique. Leur origine se situe dans la mer Adriatique où elles se détachent des tourbillons comme dans la formation des meddies de la péninsule ibérique (tourbillons d'eau méditerranéenne dans l'océan Atlantique). D'une année sur l'autre, la création de ces lentilles d'eau froide semble soumise à des grandes variations (C) 2000 Ifremer/CNRS/IRD/Éditions scientifiques et médicales Elsevier SAS

masse d'eau / lentille / meddy / Ionienne / Adriatique

\section{INTRODUCTION}

The Ionian Sea being the central basin of the Mediterranean Sea, is subject to potential inflow of water from the Levantine, Aegean, Adriatic and western Mediterranean Seas. The temperature and salinity

Abbreviations: $\mathrm{ASW}=$ Adriatic Surface Water; $\mathrm{CTD}=$ Conductivity, Temperature, Depth (actually pressure); EMDW = Eastern Mediterranean Deep Water; ISW = Ionian Surface Water; LIW = Levantine Intermediate Water; MAW = Modified Atlantic Water; POEM $=$ Physical Oceanography of the Eastern Mediterranean; $\mathrm{XBT}=$ Expendable $\quad$ BathyThermograph $; \quad \mathrm{XCTD}=$ Expendable CTD probe; $\mathrm{XSV}=$ Expendable Sound Velocity probe.

* Correspondence and reprints: sellscho@saclantc.nato.int distributions of the Ionian deep, intermediate and surface waters reflect the contributions from the adjacent seas. Systematic hydrographic surveys of the eastern Mediterranean began early in this century [9]. The latest comprehensive synthesis of the Ionian Sea hydrography [7] is the result of many years of focused collaborative effort of many researchers.

The circulation conditions in the eastern Mediterranean turned out to be less stable than it was believed for many years. Changes in the eastern Mediterranean Deep Water were found in 1995 [13] indicating the Adriatic Sea being replaced as a source for Ionian Sea deep water by the Aegean Sea. A prominent role of the Aegean as a deep water supply 
has already been noted by Nielsen [9], but was declined by Pollak [11], whereas to Wüst [14] it "seems probable that some smaller influences come from the Aegean Sea by occasional overflow".

The same lack of persistence as with the origin of Ionian Sea deep water is noticed at the surface. In the light of the findings during the last decade, the circulation pattern and resulting temperature and salinity distributions in the Ionian Sea cannot be presumed to be invariant. Even though the stream of Modified Atlantic Water (MAW) in three consecutive years was observed to enter the Ionian Sea at the Malta Plateau shelf break and proceed towards NNE [12], this does not prove a permanent anticyclonic circulation of MAW in the Ionian Sea. Numerical simulations of the interannual variability [10] revealed drastic changes of the flow pattern in the Ionian Sea caused by different atmospheric forcing in different years. The equilibrium point between salinity increase by evaporation and freshening by surface inflow from the Adriatic Sea and the Sicilian Channel is not fixed over a period of years. Evidence of a shift was found in the Strait of Messina [2].

The physical properties of the seawater as functions of depth and position are important environmental parameters in ocean acoustics trials. As a necessary supplement to climatological means, usually expendable bathythermographs (XBT) are deployed. Sound velocity is calculated from temperature and standard salinity taken from climatology. Sometimes also expendable sound velocity probes (XSV) are used for direct measurement of the sound speed profile. The data set presented here consists of a large number of casts in a confined area in the central Ionian Sea. In two isolated patches, a subset of profiles reveals surprisingly large deviations from the rest of the measurements and from expectations based on climatology. In this paper, we will demonstrate the oceanographic situation, identify the unusual water mass by a best guess of salinity and provide an explanation for the origin of the atypical water in the Ionian Sea.

\section{MATERIAL AND METHODS}

\subsection{The data}

65 XBTs and 6 XSVs were deployed during a sea trial of the NATO Research Vessel Alliance between 27 September and 5 October 1996. The casts are located on the perimeter of a $270 \times 150 \mathrm{~km}$ box. Their positions are displayed in the geographical overview of figure 1 . The temperature and sound velocity profiles falling into three classes I, II and III are displayed in different rows of figure 2. Class I consists of the 'normal' profiles. The surface mixed layer has a temperature of about $24^{\circ} \mathrm{C}$ on the southern line and $23{ }^{\circ} \mathrm{C}$ in the north. The temperature drops off by several degrees within a few metres in the thermocline and then gradually diminishes to approximately $14{ }^{\circ} \mathrm{C}$ at $200 \mathrm{~m}$. Between 200 and $400 \mathrm{~m}$, minor deviations from an isothermal trace are present in some of the profiles. Below $400 \mathrm{~m}$, the temperature slightly decreases again and reaches a minimum of approximately $13.5^{\circ} \mathrm{C}$ at $1000 \mathrm{~m}$. No remarkable temperature change occurs on the low profile end down to $1800 \mathrm{~m}$ (not shown in the figures). The sound velocity counterpart of the temperature profiles reflects the combined influence of temperature and pressure at nearly constant salinity.

Class II profiles show another sharp thermocline with gradient $-75 \mathrm{mK} \cdot \mathrm{m}^{-1}$ at approximately $200 \mathrm{~m}$ depth, a nearly isotherm layer of $12.5^{\circ} \mathrm{C}$ extending to about $300 \mathrm{~m}$ depth, and a 100-m-wide transition layer where the temperature increases by $15 \mathrm{mK} \mathrm{m}^{-1}$ to the climatological $14{ }^{\circ} \mathrm{C}$ value below. The area between profiles of this category and class I profiles is equivalent to a heat deficit of about $1.3 \times 10^{9} \mathrm{~J} \cdot \mathrm{m}^{-2}$. Similarly, in class III, the temperature deviates from normal in the depth range from 240 to $470 \mathrm{~m}$. The heat deficit has the same order of magnitude as in class II, but the cold anomaly lies more than $50 \mathrm{~m}$ deeper, the minimum temperature is slightly higher and the transition to adjacent layers weaker.

All class II and III profiles were observed in two well defined patches that exclusively contain profiles of the respective class (figure 3). Class II is located in the centre of the eastern line, class III in the western half of the northern line. The patches are not fully surrounded by observations of 'normal' profiles, the eastern patch is open towards west and east, the western patch is open to southwest. Tentatively, circles were drawn with diameters of 15 nautical miles $(27.8 \mathrm{~km})$ representing the patches. Not only the core temperatures but also the vertical extensions of the cold water masses in the circles are remarkably con- 
sistent. In figure 2, two casts from the transition zone south of the eastern circle are included in the set of class II profiles. One transitional profile from southeast of the western circle is displayed with the class III set. These three profiles were omitted from the class I set in figure 2. In the eastern patch, the station with the widest vertical extension of the cold lens is the one closest to the centre of the circle. In the western patch, the maximum depth range of the cold water lies in the southwest, which may be a hint that a bigger patch extending further southwest might be closer to reality than the circle shown in the figure.
Because of the different depths of the two cold water bodies indicating slightly different densities, it is unlikely that the patches are tongues of the same contiguous area. The different shape of the temperature profile also suggests that the patches are disconnected. Finally for dynamical reasons, as will be explained later, it seems adequate to presume two isolated approximately circular lenses. Not surprisingly, satellite surface temperature of that time period does not exhibit any indication in the area of the central Ionian Sea that could be interpreted as a signature of the dramatic sub-surface event. The shal-

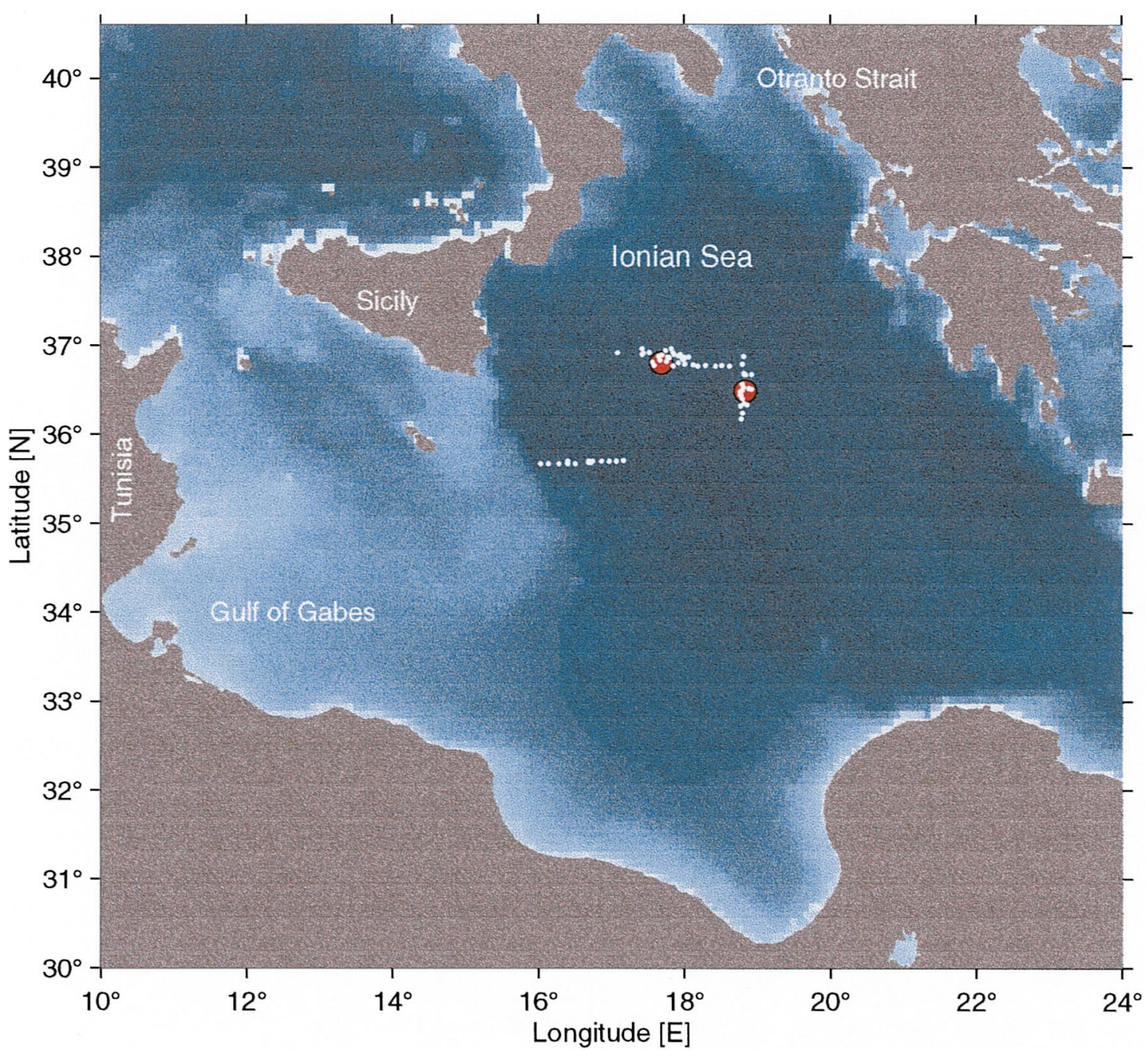

Figure 1. XBT and XSV deployment positions in the Ionian Sea in autumn 1996. The red circular patches indicate the positions of two cold lenses below the thermocline. 

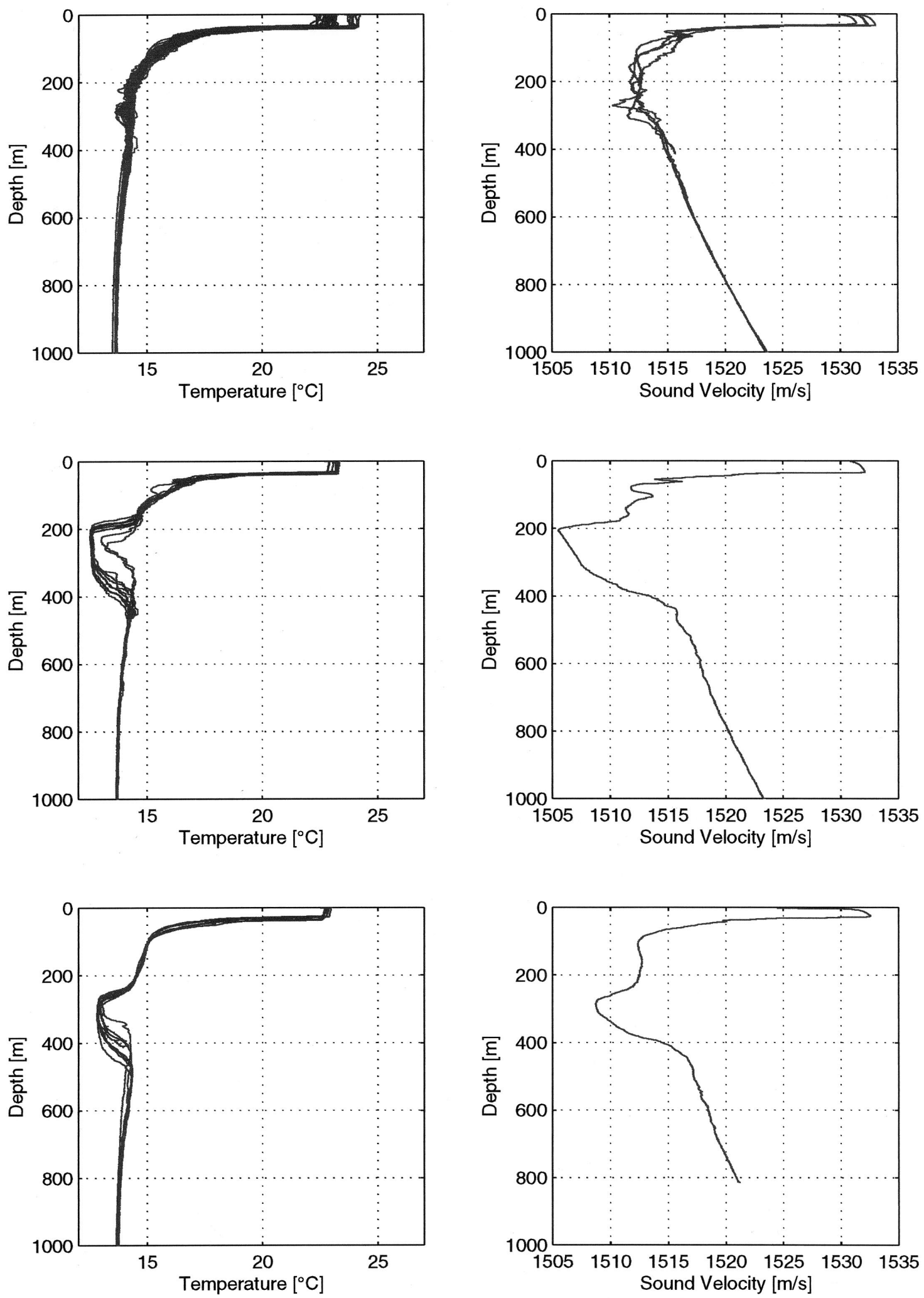

Fig. 2. 
low pynocline prevents the low sub-surface temperature from outcropping.

Salinity, which is needed for better water mass identification and the estimation of geostrophic balance, was not measured during the trial. However, the equation for the calculation of sound velocity from salinity, temperature and pressure [4] can be used to compute salinity from sound velocity, temperature and depth. The accuracy of the calculated salinity is a weighted combination of the accuracies of measured temperature and sound velocity. XBT and XSV probes have nominal accuracies of $0.15 \mathrm{~K}$ and 0.25 $\mathrm{m} \cdot \mathrm{s}^{-1}$. The dependency of sound velocity on temperature and salinity amounts $3.3 \mathrm{~m} \cdot \mathrm{s}^{-1} \cdot \mathrm{K}^{-1}$ and 1.3 $\mathrm{m} \cdot \mathrm{s}^{-1}$ respectively (note that salinity according to the practical salinity scale is dimensionless). The nominal error of calculated salinity from a simultaneous XBT and XSV measurement thus becomes 0.63 , which is too large for a satisfactory water mass identification. The nominal error of calculated density becomes 0.52 $\mathrm{kg} \cdot \mathrm{m}^{-3}$, again too large for ocean dynamics considerations. There is a requirement for the reduction of error margins.

To make things worse, there was no simultaneous measurement of temperature and sound velocity performed in a cold lens. Instead, for the calculation of salinity, two profiles were combined which are separated by $18 \mathrm{~h}$ in time and $6.5 \mathrm{~km}$ in location. The positions are encircled on the map of figure 3. The error introduced by the combination of these profiles is considered to be bigger than potential depth errors due to imperfectly known fall rates of the expendable instruments. A shift in the vertical position of a layer or an inaccurate measurement of its depth results in an additional error $\delta \mathrm{X}=\partial \mathrm{X} / \partial \mathrm{z} \mathrm{dz}$ of a measured variable $\mathrm{X}$, where $\delta \mathrm{z}$ and $\partial \mathrm{X} / \partial \mathrm{z}$ are the depth uncertainty and the vertical gradient of that variable. In depth ranges with large vertical gradients such as the thermocline and the upper and lower boundary of the cold lens, the combination of unadjusted temperature and sound velocity profiles leads to unreliable values (salinity spikes). In the weak gradient in the eastern cold lens on the other hand, the temperature measurement is not degraded much by a depth error of several tens of metres. Even with the unsatisfactory result of the error analysis, the combination of temperature and sound velocity profiles provides valuable insight for the salinity and density profile anomalies, when compared with measurements at approximately the same position but in a different year.

In the upper left of figure 3, the XBT and XSV profiles of autumn 1996 are displayed together with the respective curves of a CTD (conductivity, temperature, depth) measurement acquired in the same area eleven months later (see below). Except for the cold water portion, XBT and XSV profiles are so similar to their CTD counterpart that it is justified to use the 1997 profile also for comparison of calculated salinity and density. As it can be assumed that below $600 \mathrm{~m}$ the interannual variation of potential density is smaller than the difference between the two curves in the lower right of figure 3, the difference between the at-depth densities calculated from the expendable devices in 1996 and the CTD measurement in 1997 is a measure for the actual error introduced by the XBT or XSV inaccuracy or both. It is one order of magnitude smaller than the nominal accuracy given above. A nearly perfect match between profiles of all variables can be achieved by a shift of the XBT measurement to lower temperatures by only $30 \mathrm{mK}$.

Measurement errors of expendable devices are primarily due to a constant offset and only secondarily related to an environmental parameter. If it can be assumed that the XBT and XSV errors do not change significantly with depth and that their temperature dependence can be neglected in the temperature range from 12.5 to $15^{\circ} \mathrm{C}$, then the salinity and density determined between 100 and $600 \mathrm{~m}$ depth should have approximately the same precision as at greater depth. Only in those parts of the profile where the vertical temperature gradient is not small, the calculation is degraded by the above-mentioned reasons. The computed salinity peaks at 200 and 400 m caus-

Figure 2. Entirety of XBT and XSV profiles east of $16^{\circ} 30^{\prime} \mathrm{E}$ showing the existence of two separate cold lenses. Upper row: profiles not located in one of the circular areas exhibit nearly uniform conditions in the central Ionian Sea. Central row: profiles in the area enclosed by a circle with radius 7.5 nautical miles around $36^{\circ} 29^{\prime} \mathrm{N}, 18^{\circ} 50^{\prime} \mathrm{E}$. Two transient profiles from outside the circle, close to the southern edge are included. Lower row: profiles in the area enclosed by a circle with radius 7.5 nautical miles around $36^{\circ} 48^{\prime} \mathrm{N}, 17^{\circ} 41^{\prime} \mathrm{E}$. A transient profile from outside the circle, close to the southeastern edge is included. 
ing the unrealistic density peaks at the same depths are due to the misfit of XBT and XSV cold lens boundary positions. At least for the part of the profile between 200 and $300 \mathrm{~m}$, in the cold water lens, it appears justified to state a salinity between 37.8 and 38 and a potential density anomaly between 28.7 and $28.9 \mathrm{~kg} \cdot \mathrm{m}^{-3}$. The space between isopycnals becomes wider in the depth interval of the lens. The 28.9 to $29.1 \sigma_{\mathrm{t}}$ levels are pushed down by $100 \mathrm{~m}$. The
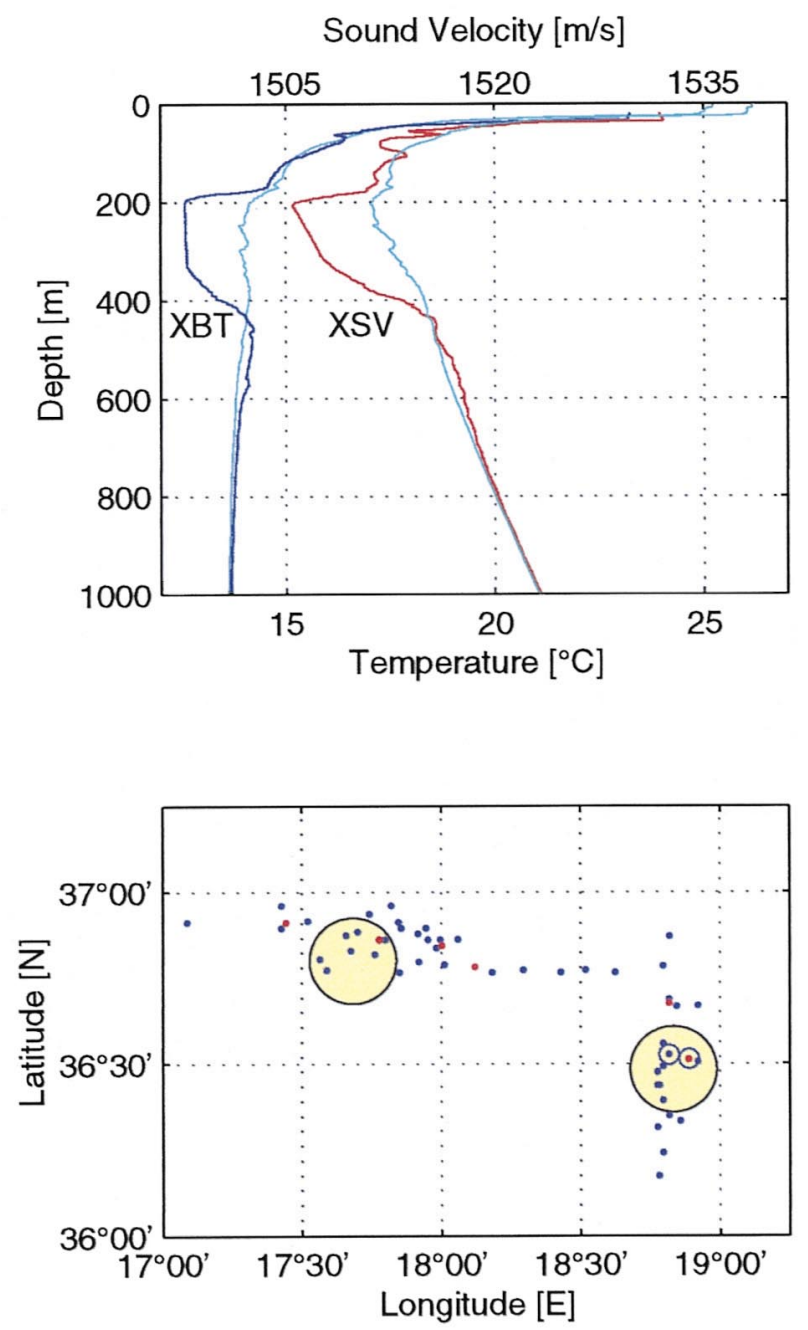

lens must rotate anticyclonically in order to be geostrophically balanced.

The crude calculation of density profiles at the position of the lens leads to a rough estimate of the lens dynamics only. The difference between the geopotential anomaly inside and outside the lens at the same depth is between 0.1 and $0.2 \mathrm{~m}^{2} \cdot \mathrm{s}^{-2}$. Its maximum horizontal gradient close to the lens boundary could
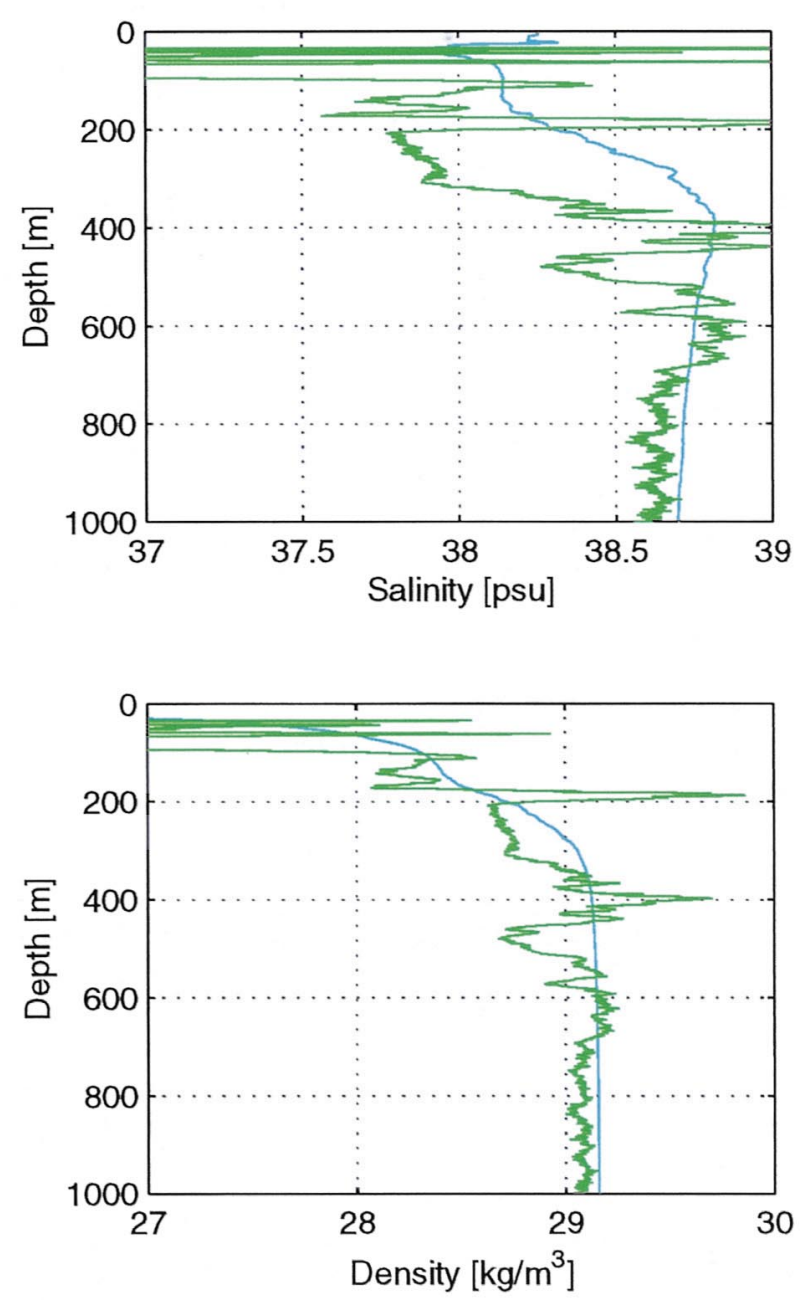

Figure 3. The water mass of the eastern lens. The dark blue and red curves in the upper left are the temperature and sound velocity profiles taken at the encircled positions (lower left). For reference, the respective (light blue) profiles are added from a CTD cast in 1997 in the same area. Salinity (upper right) and density (lower right) are calculated by combination of the XBT and XSV profiles and displayed in green. Again, the 1997 data are added in light blue. In the map in the lower left, XBT positions are marked by blue points and XSV by red points. The lenses are indicated by yellow circles. 
be close to $10^{-4} \mathrm{~m} \cdot \mathrm{s}^{-2}$, which would balance a geostrophic maximum azimuthal velocity of almost $1 \mathrm{~m} \cdot \mathrm{s}^{-1}$. At this high current velocity, the nonlinear term in the gradient wind balance becomes important [3], which in turn would explain the apparent sharp boundary of the lens.

In the western lens, the results are similar to those shown in figure 3. However, larger errors are introduced by the shape of the temperature profile that does not contain a wide range of nearly constant low temperature.

\subsection{The situation one year later}

One year later, in late summer of 1997, a dense network of CTD stations in the Ionian Sea was surveyed by several ships during the sea trial Rapid Response 97 (upper left of figure 4). No cold lens comparable with those in figure 2 was found in the entire Ionian Sea. The line of circles on the map indicates a section with five CTD deployments and two casts of expendable CTD devices (XCTD) accomplished by Alliance on 6 September 1997. It leads through the area where the cold lenses were found in 1996. In the profile data, the usual temperature minimum between the thermocline and the LIW (Levantine Intermediate Water) salinity maximum is evident, but only at temperatures of $13.7^{\circ} \mathrm{C}$ or more. Some of the profiles exhibit MAW with salinity down to 37.5 in the lower part of the thermocline. In the central part of the section, there is a water mass present in the depth interval from 100 to $200 \mathrm{~m}$ with salinity below 38.2 and temperature between 14 and $15^{\circ} \mathrm{C}$. It is less dense than the water at both ends of the section at the same depth. Therefore, the 28.5 to 29.1 isopycnals are displaced downwards by more than $100 \mathrm{~m}$ in the centre of the section. The same result as in the section of Alliance in figure 4 was found in the CTD stations on the intersecting track of another ship, the Planet, and on the parallel track to the north of Alliance, but not in CTD stations north of $38^{\circ} \mathrm{N}$. The sub-surface relatively fresh water mass in the central Ionian Sea that was cut in the section of figure 4, has a diameter of approximately $150 \mathrm{~km}$, which is an order of magnitude larger than the cold lenses of 1996. On-track current measurements and dynamical analysis carried out with the 1997 CTD data reveal an anticyclonic eddy centered at $37^{\circ} 30^{\prime} \mathrm{N}, 17^{\circ} 45^{\prime} \mathrm{E}$. The salinity of 38.2 below the thermocline is the same as of ISW (Ionian Surface Water) in the northern Ionian Sea during the winter and spring cruises of the Otranto project [5]. MAW meets the low salinity but with $15^{\circ} \mathrm{C}$ in winter it hardly meets the low temperature of this water mass. Therefore ASW (Adriatic Surface Water) with salinities between 37 and 38.3 and temperatures between 11 and $13{ }^{\circ} \mathrm{C}[5,8]$ is probably the stronger source for the water trapped in the eddy. The water exchange through the Strait of Otranto is sufficiently large [5] to feed the eddy during a single winter season. The same kind of eddy had been present also in the POEM-AS87 cruise [7] centered at $36^{\circ} 45^{\prime} \mathrm{N}$, $17^{\circ} 30^{\prime} \mathrm{E}$.

The subthermocline water mass crossed by the CTD station line of figure 4 is certainly not a reminiscence of the cold spots observed in 1996 at the same location. There is one CTD profile, however, in the 1997 data set with a temperature minimum of $13{ }^{\circ} \mathrm{C}$ and 38.05 salinity at $250 \mathrm{~m}$ depth that shows similarity with the 1996 data. It was taken by Alliance on 7 September 1997 in continuation of the track discussed above as the first after the alteration of the course towards NE. Its position is $37^{\circ} 28.6^{\prime} \mathrm{N}$, $15^{\circ} 58.4^{\prime} \mathrm{E}$. The profile data are displayed in figure 5 together with their neighbours on the track. Note that only the nearest station towards the SE has a small indication of the low temperature peak. It is missing for the rest of CTD stations in the vicinity, also in the profiles not presented in figure 5. The small diameter of the cold lens, its low temperature and salinity makes it conceivable that it endured from 1996, or was created in the winter 1997 by the same mechanism as the cold lenses observed in 1996. The dynamic analysis of 8 September 1997 exhibits a small anticyclone centered at $37.5^{\circ} \mathrm{N}, 16^{\circ} \mathrm{E}$.

\section{DISCUSSION}

The surface water of the central Ionian Sea has a salinity well above 38 and it never cools down to $13{ }^{\circ} \mathrm{C}$ or less. The cold and fresh spots trapped in anticyclonic eddies and observed in 1996 were advected from a place favourable for their generation at least for a short period in winter. The MAW of the Atlantic Ionian Stream has sufficiently low salinity, but in the Sicilian Channel, the surface water in 

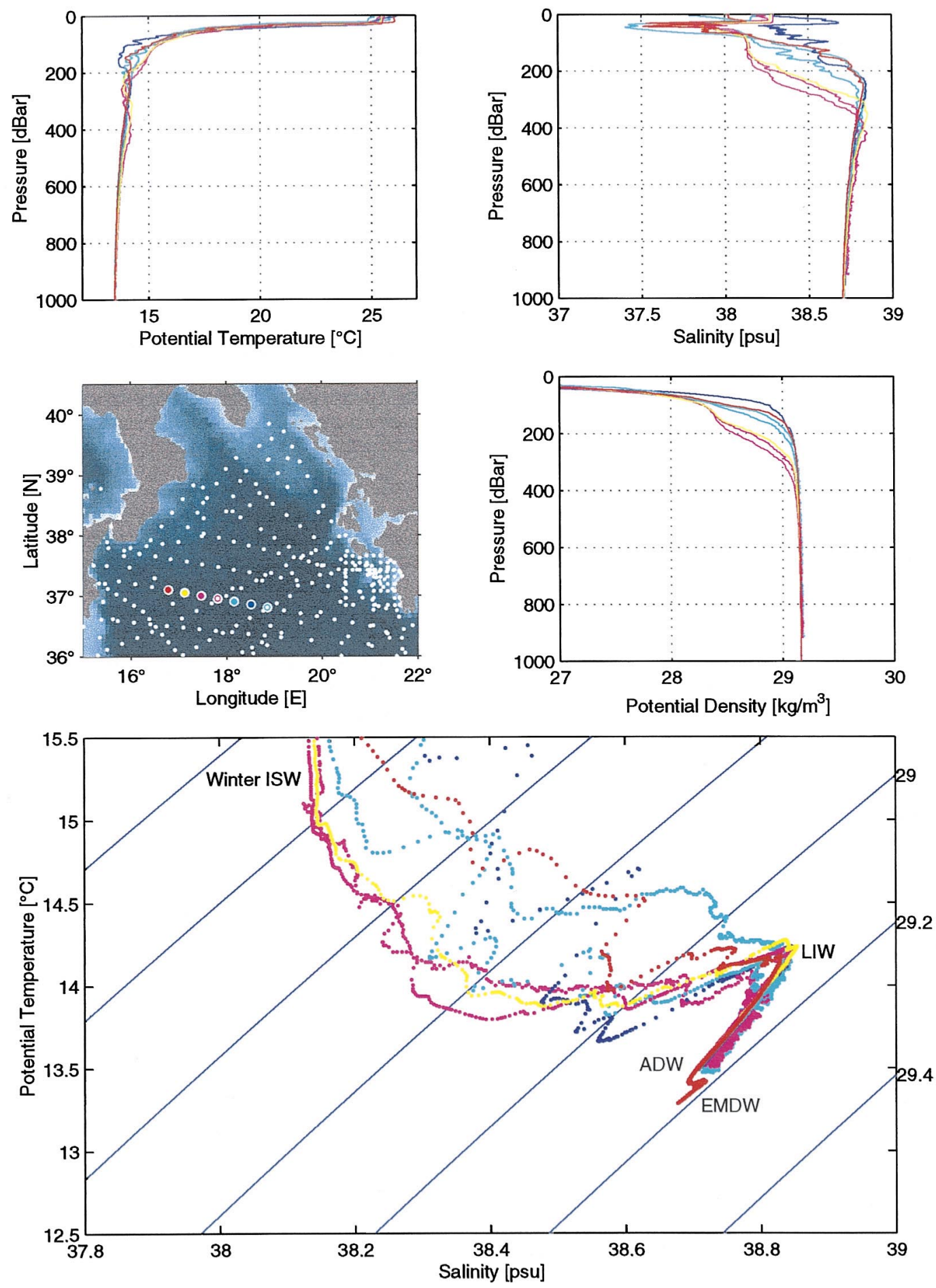

Figure 4. CTD section of 6 September 1997. Positions of stations (centre left) are marked with the same colour as the curves in the diagrams. ISW of the preceding winter with salinity below 38.2 and potential density anomaly below $28.5 \mathrm{~kg} \mathrm{~m}^{-3}$ is present in the central profiles where it fills the depth range between the thermocline and the LIW. The downward displacement of the isopycnals is geostrophically balanced by anticyclonic rotation. In the thermocline, low salinity peaks are due to Atlantic Water inflow and the high salinity peak to advection of surface water from the southeast. 

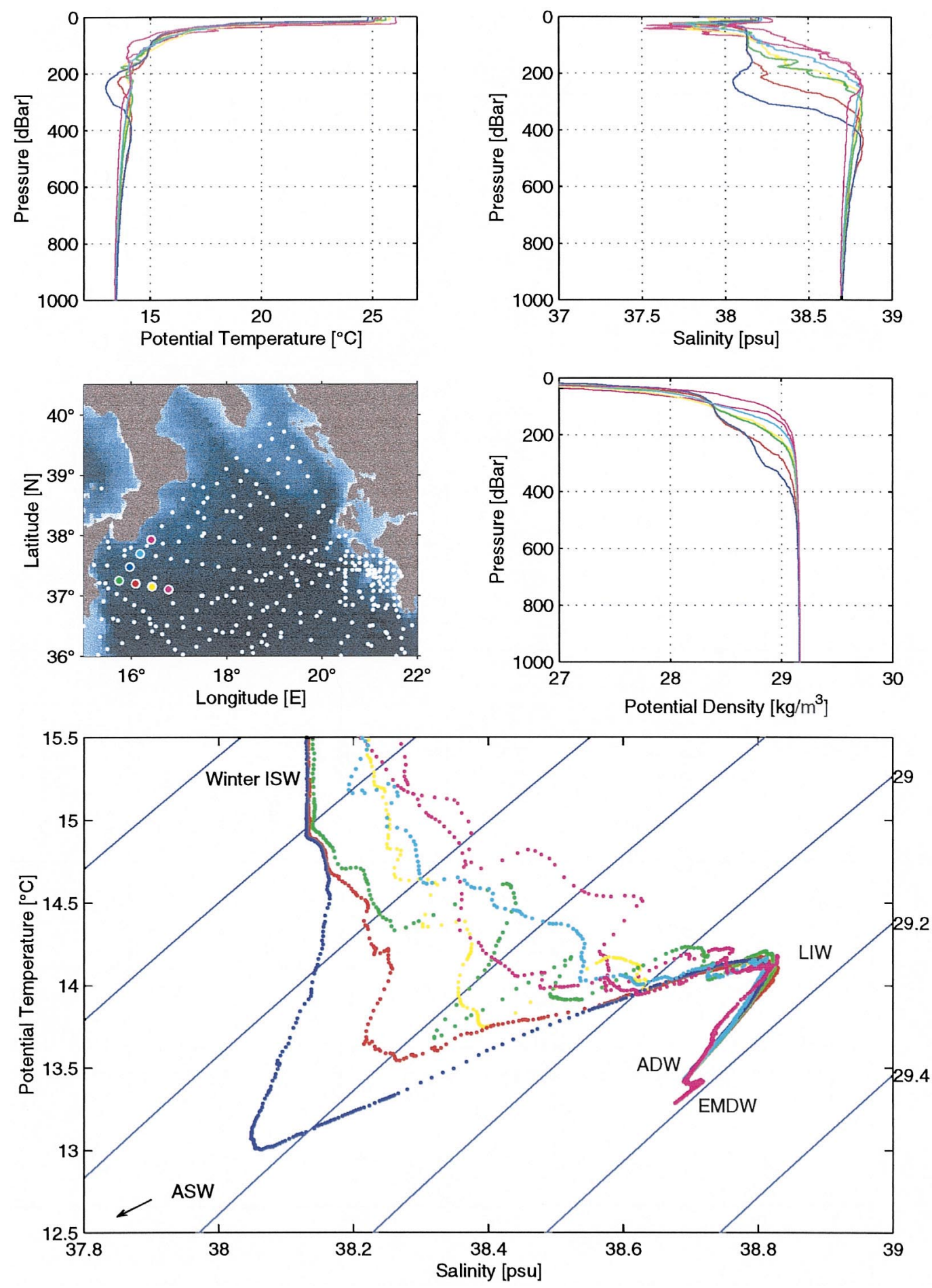

Figure 5. CTD section of 7 September 1997. Positions of selected stations are indicated by circles (centre left). A small lens of water cooler than winter ISW is evident in the data of the station northeast of and next to the corner point of the indicated track, and has some manifestation in the data of a neighbour in the south. 


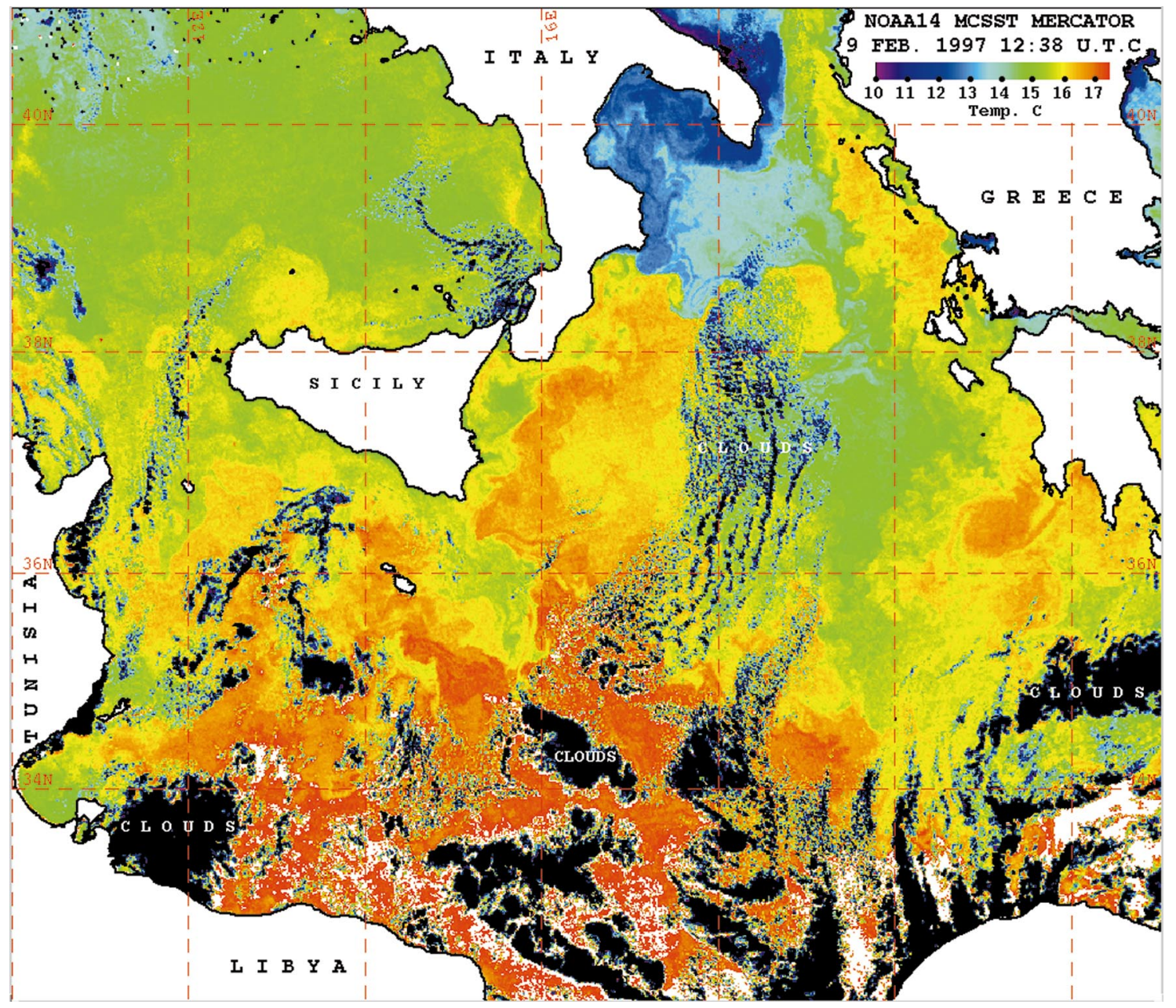

Figure 6. Satellite image of sea surface temperature on 9 February 1997. Cold ASW leaves the Adriatic Sea and follows the Italian coast in the Gulf of Taranto.

winter is approximately $15^{\circ} \mathrm{C}$. Therefore the strongest candidate for the source of the cold lenses is the Adriatic Sea.

In response to the atmospheric conditions, the characteristics of the Adriatic waters undergo significant interannual changes. The winter cruise in 1994 [5] shows ASW with a temperature as cold as $12{ }^{\circ} \mathrm{C}$ at salinity 37.4. Mixing products of ASW with the underlying LIW lie on a straight line connecting the two water types in a temperature-salinity plot. The cool water mass of the single station in figure 5 has properties half way between ASW and LIW with a small percentage of ISW added. Therefore it seems likely that its origin is the Adriatic Sea. Outflow from the Adriatic Sea through the Strait of Otranto occurred close to the Italian coast. Then, being heavier than the ISW, the ASW may have been subducted and eventually pinched off from the coastal current at a sharp turn to the right of the coastline. If this explanation holds, the mechanism of the separation is equivalent to the generation of meddies at the Iberian peninsula $[1,6]$.

Cloud-free images of surface temperatures measured by NOAA 12 and NOAA 14 satellites in the winter months of 1996 to 1998, all show similar temperature distributions in the Strait of Otranto and the Ionian Sea. The example of 9 February 1997 is given in figure 6. The ASW that leaves the Adriatic Sea is colder than $12{ }^{\circ} \mathrm{C}$ in February. It forms eddies and 
meanders along the Italian coast almost down to the southern tip. According to historical data, the final transformation to ISW generally seems to produce moderate horizontal temperature and salinity gradients rather than spectacular patches such as those found in 1996. Note that the water mass in 100 to 200 $\mathrm{m}$ depth in the section through the large anticyclone in figure 4 has the characteristics of winter ISW as contained in the data of a February 1994 cruise [5]. In the $\mathrm{T}$-S-diagram at the bottom of figure 4, winter ISW has the salinity 38.14 at temperatures above $14.8^{\circ} \mathrm{C}$ and density anomaly below 28.4 .

In the optimistic expectation of possibly tracking the cold lenses, the 1996 XBT data set of a military database was scanned for low temperatures at inter- mediate depth in the Ionian Sea. All XBT casts might have accidentally missed the lens positions. On the other hand, it is not unlikely that existing profiles from the lenses were discarded because of their large deviation from climatology. Since also the dense CTD data set from the 1997 survey of the Ionian Sea contains only one small cool lens, that is however warmer and much less impressive than the patches in 1996, we were looking for specific conditions in winter 1996 that were not present in the following year. In winter 1996 , temperatures below $12{ }^{\circ} \mathrm{C}$ were observed in the very shallow area at about $35^{\circ} \mathrm{N}$, $11.5^{\circ} \mathrm{E}$ on the Tunisian Plateau (figure 7), whereas in the winter of 1997 (figure 6), the Tunisian shelf waters are much warmer. Shelf convection caused by cooling of MAW would create subsurface water of

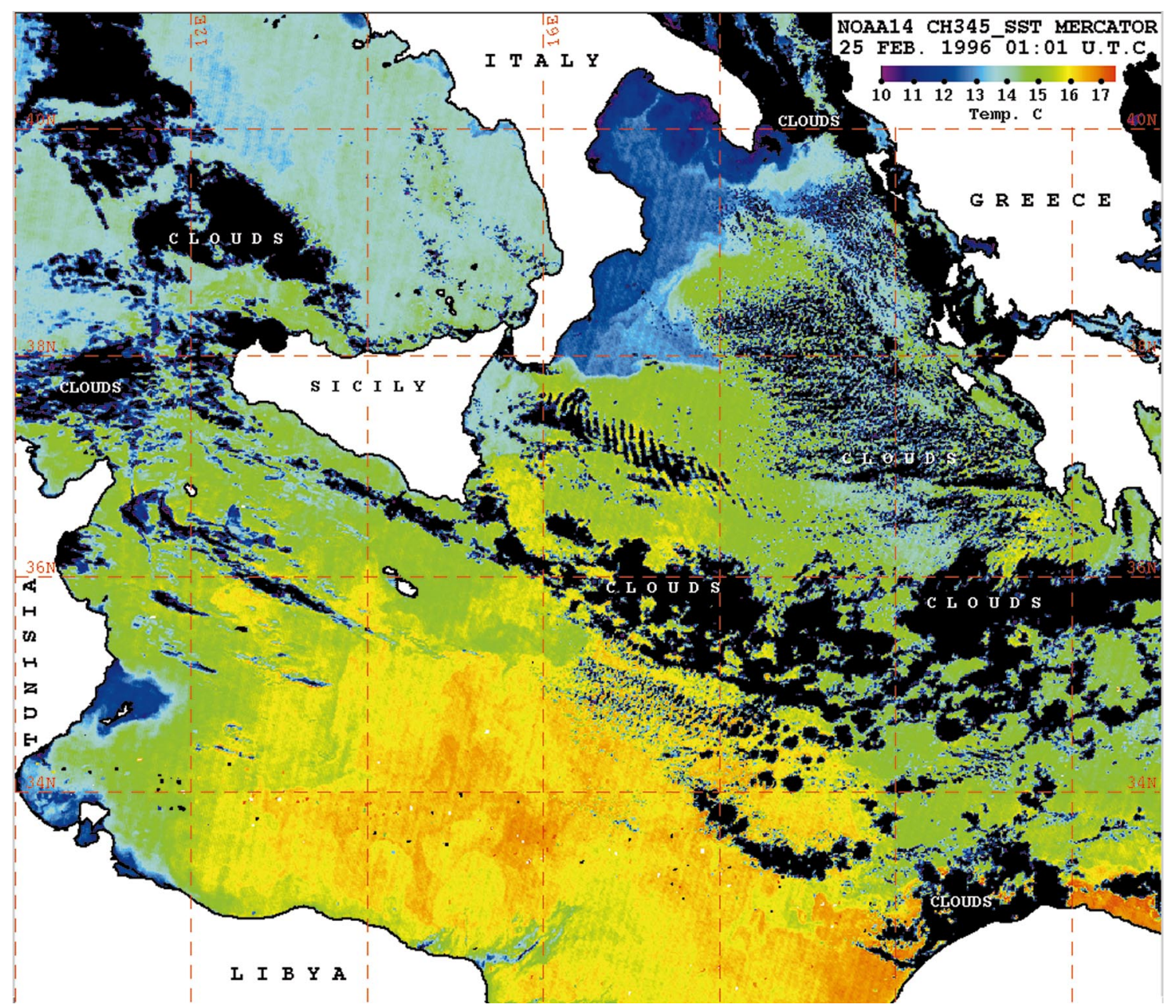

Figure 7. Satellite image of sea surface temperature on 25 February 1996. Cold ASW has proceeded down to the tip of the Italian peninsula. Another cold water mass has formed on the shallow shelf on the Tunisian coast. 
the required $\mathrm{T}-\mathrm{S}$ characteristic. In an Alliance cruise in February 1999, it was observed as a bottom layer in the Gulf of Gabes that spreads along the African coastal slope. By interaction with the overlying water, it gains salt and heat before it arrives at deeper parts of the Ionian Sea. The Tunisian shelf thus is excluded as a potential origin of the observed cold lenses.

\section{CONCLUSION}

The circulation in the Ionian Sea varies on the time scale of years leading to shifts in observed parameters. But even ocean features observed in one year need not be present in another year. In autumn 1996, two water lenses as cold as $12.5^{\circ} \mathrm{C}$ were observed in the Ionian Sea between the thermocline and the LIW salinity maximum, having diameters close to $30 \mathrm{~km}$ and volumes of $60 \mathrm{~km}^{3}$.

If similar cold water lenses have never been reported before, they may not have been present before 1996, or they were missed by the coarse horizontal resolution of oceanographic surveys, or isolated measurements exposing this unusual water mass were not trusted. The measurements obtained during an ocean acoustics trial in autumn 1996 are consistent and sufficiently dense to resist skepticism. The small volume of cold water may be of minor influence for the overall water mass circulation in the Ionian Sea. For the acoustic experiment, however, it is important because of the changing sound velocity profiles and their non-negligible impact on sound propagation conditions.

During a detailed ocean survey in 1997, an equally small but less cold lens was found in the Ionian Sea. Its salinity and anticyclonic rotation are consistent with the assumptions made for the 1996 lenses. Two possible origins and mechanisms for their generation in February are discussed for the cold lenses, Adriatic Surface Water pinched off south of Otranto and Modified Atlantic Water cooled down on the shallowest part of the Tunisian shelf.

\section{Acknowledgements}

J. Redmayne kindly provided the data from an ocean acoustics trial and drew the author's attention to the strange behaviour of many temperature profiles. We also thank N. Portunato and G. Baldasserini for profile data processing and E. Nacini for preparing the satellite images of ocean surface temperature.

\section{REFERENCES}

[1] Bower A.S., Armi L., Ambar I., Direct evidence of meddy formation off the southwestern coast of Portugal, Deep-Sea Res. I 42 (1995) 1621-1630.

[2] Brandt P., Rubino A., Quadfasel D., Alpers W., Sellschopp J., Fiekas H.-V., Evidence for the influence of Atlantic-Ionian Stream fluctuations on the tidally induced internal dynamics in the Strait of Messina, J. Phys. Oceanogr. 29 (1999) 10711080.

[3] Elliot B.A., Sanford T.B., The subthermocline lens D1, part II: kinematics and dynamics, J. Phys. Oceanogr. 16 (1986) $549-561$.

[4] Fofonoff N.P., Millard R.C., Algorithms for computation of fundamental properties of seawater, Unesco Techn. Pap. Mar. Sci. 44 (1983) 53.

[5] Gacic M., Kovacevic V., Manca B., Papageorgiou E., Poulain P.M., Scarazzato P., Vetrano A., Thermocline properties and circulation in the Otranto Strait, Bull. Inst. Océanogr., Monacon $\mathrm{n}^{\circ}$ sp. 17 (1996) 117-144.

[6] Jungclaus J.H., A three-dimensional simulation of the formation of anticyclonic lenses (meddies) by the instability of an intermediate depth boundary current, J. Phys. Oceanogr. 29 (1999) 1579-1598.

[7] Malanotte-Rizzoli P., Manca B.B., Ribera d'Alcalà M., Theocharis A., Bergamasco A., Bregant D., Budillon G., Civitarese G., Georgopoulos D., Michelato A., Sansone E., Scarazzato P., Souvermezoglou E., A synthesis of the Ionian Sea hydrography, circulation and water mass pathways during POEM-Phase I, Progr. Oceanogr. 39 (1997) 153-204.

[8] Manca B., Giorgetti A., Thermohaline properties and circulation patterns in the southern Adriatic Sea from May 1995 to February 1996, Atti del XII Congresso della Associazione Italiana di Oceanologia e Limnologia, Isola di Vulcano, 1821 Settembre 1996, Piccazzo M. (Ed.), Genova 1998, Vol. II, 399-414.

[9] Nielsen J.N., Hydrography of the Mediterranean and adjacent waters, Rep. Danish Oceanogr. Exped. Medit. 1 (1912) $77-$ 192.

[10] Pinardi N., Korres G., Lascaratos A., Roussenov V., Stanev E., Numerical simulations of the interannual variability of the Mediterranean Sea upper ocean circulation, Geophys. Res. Lett. 24 (1997) 425-428.

[11] Pollak M.J., The sources of the deep water of the eastern Mediterranean Sea, J. Mar. Res. 10 (1951) 128-152.

[12] Robinson A.R., Sellschopp J., Warn-Varnas A., Leslie W.G., Lonzano C.J., Haley P.J., Anderson L.A., Lermusiaux P.F.J., The Atlantic Ionian Stream, J. Mar. Syst. 20 (1998) 129-156.

[13] Roether W., Manca B.B., Klein B., Bregant D., Georgopoulos D., Beitzel V., Kovacevic V., Luchetta A., Recent changes in the Eastern Mediterranean deep water, Science 271 (1996) $333-335$.

[14] Wüst G., On the Vertical Circulation of the Mediterranean Sea, J. Geophys. Res. 66 (1961) 3261-3271. 